\title{
PCM Heat Storage Charged with a Double-Reflector Solar System
}

\author{
Amos Veremachi, ${ }^{1}$ Boaventura Chongo Cuamba, ${ }^{1}$ Azher Zia, \\ Jorgen Lovseth, ${ }^{3}$ and Ole Jorgen $\mathrm{Nydal}^{4}$ \\ ${ }^{1}$ Department of Physics, Eduardo Mondlane University, Avenida Julius Nyerere 3455, P.O. Box 257, Maputo, Mozambique \\ ${ }^{2}$ Department of Physics, Uppsala University, Uppsala, Sweden \\ ${ }^{3}$ Department of Physics, Norwegian University of Science and Technology (NTNU), Trondheim, Norway \\ ${ }^{4}$ Department of Energy and Process Engineering, Norwegian University of Science and Technology (NTNU), \\ Kolbjørn Hejes vei 1B, 7491 Trondheim, Norway
}

Correspondence should be addressed to Amos Veremachi; averemachi@gmail.com

Received 23 March 2016; Accepted 15 June 2016

Academic Editor: Charles M. Drain

Copyright (C) 2016 Amos Veremachi et al. This is an open access article distributed under the Creative Commons Attribution License, which permits unrestricted use, distribution, and reproduction in any medium, provided the original work is properly cited.

\begin{abstract}
A "Solar Salt" ( $\mathrm{NaNO}_{3}-\mathrm{KNO}_{3} 60: 40$ molar mixture) latent heat storage has been charged by direct solar illumination. Solar Salt as a Phase Change Material (PCM) can be an attractive small scale heat storage solution, as the melting temperature of about $220^{\circ} \mathrm{C}$ can be suitable for cooking purposes. The tests were made with a double-reflector setup. In this setup a secondary reflector positioned above the focal point of the primary reflector directs the rays onto a heat storage positioned below a hole in the primary reflector. The reflectors are tracking the sun, but the storage is stationary. The direct illumination of the absorber top plate during the tracking of the sun melted the salt in the storage through conducting fins. This is a system where portable heat batteries can be charged, during sunshine hours, and then provide heat for cooking during evening times.
\end{abstract}

\section{Introduction}

The majority of the population in Mozambique lives dispersed in rural areas, with nearly $75 \%$ of the population not connected to the electrical grid. Most people in Mozambique rely on some form of biomass for cooking; more than $80 \%$ of the country's primary energy comes from biomass [1]. The biomass resources for cooking are, however, becoming increasingly scarcer due to deforestation and to the change in land use [2,3]. The deforestation rate in Mozambique is estimated to $5.6 \%$ [4]. This also increases the burden on women and children who spend increasing time on fetching firewood to meet the families daily energy needs for cooking.

Mozambique has good solar radiation intensity with a daily annual average of $5.2 \mathrm{kWh} / \mathrm{m}^{2}[1,2,5]$. Therefore, direct collection of solar thermal energy can be an energy source for multiple domestic needs (cooking, baking, frying, hot water, pasteurization, etc.) in rural areas of Mozambique, both as stand-alone units or as units integrated in hybrid systems (solar PV, wind, and hydropower). Adoption of solar cooking also has other indirect benefits such as more time for women and children to dedicate themselves to their educational activities; improved in-door environment; and less risk of burning accidents.

Solar Cooker International (SCI) [6] provides extensive information on solar cookers. The most widespread solar cooker technology is that of direct cookers. The direct solar cookers can, however, only be used during periods of direct sunshine. So, direct cookers have limited use when the sunshine is intermittent, with the passing of clouds. The intermittency of the sunshine, the risks associated with the reflected radiation, and the lack of cultural acceptance are some of the factors which have limited the use of solar cookers in Mozambique, as discussed by Otte [7].

To overcome some of the limitations of direct solar cookers, a thermal storage can be incorporated in the solar 
system. Solar heat can then be collected while the sun is available and stored for later use. Two methods of heating can be considered. One is to use a heat transfer fluid (HTF) in a heat exchange loop between the receiver at the focal point and the heat storage (HS). The other method of direct illumination of the storage is tested here, with a doublereflector configuration.

\section{Background on Heat Storage}

2.1. Heat Storage. There are typically two common methods of storing thermal energy, as sensible heat or as latent heat. While in the former thermal energy is stored in the material by rising its temperature, in the later, thermal energy is stored during phase transition, usually close to an isothermal process. Other methods are chemically based, where energy is stored and released during chemical reactions in a reversible process.

Latent heat storage (LHS) seems to be one of the most promising forms of storing thermal energy. PCMs with a high latent heat can store and release large quantities of energy during melting and solidification, and at a constant temperature.

If the temperature of a substance, with phase change temperature $T_{\mathrm{pc}}$, is raised from $T_{1}$ to $T_{2}$ such that $T_{1}<T_{\mathrm{pc}}<$ $T_{2}$, the amount of energy $E$ stored by a material of mass $m$ and specific heat capacity $c_{P}$ is given by the expression:

$$
E_{\text {stored }}=\int_{T_{1}}^{T_{\mathrm{pc}}} m c_{P, 1} d T+m L+\int_{T_{\mathrm{pc}}}^{T_{2}} m c_{P, 2} d T .
$$

Here $c_{P, 1}$ and $c_{P, 2}$ are specific heat capacity of the material at constant pressure at the initial phase and the phase after the transition, respectively, while $L$ is a specific heat of phase transformation.

Assuming that the specific $c_{P, 1}$ and $c_{P, 2}$ do not change with temperature the above formula leads to the following linear relation:

$$
\begin{aligned}
E_{\text {stored }} & =m c_{P, 1}\left(T_{\mathrm{pc}}-T_{1}\right)+m L+m c_{P, 2}\left(T_{2}-T_{\mathrm{pc}}\right) \\
& =m\left[c_{P, 1}\left(T_{\mathrm{pc}}-T_{1}\right)+L+c_{P, 2}\left(T_{2}-T_{\mathrm{pc}}\right)\right] .
\end{aligned}
$$

Depending on the temperature range, PCMs can be used as both sensible and latent heat storage systems, as discussed further by Glatzmaier [9].

Almost all phase transitions can be considered as potential latent heat storages. Solid-liquid transitions are often preferred compared to other transitions, as the solid-liquid transition is close to incompressible; for more details see an extensive discussion by Sharma et al. [10].

In general, to be considered as a suitable storage material, PCMs should present desirable thermophysical, kinetic, and chemical properties and also the associated economical and safety issues should be addressed $[3,10]$. Indeed, as noted by [9] the major constraint of PCMs is a limitation in heat transfer during the charging and discharging cycles, generally caused by low thermal conductivity of the solid phase, which in turn leads to low power density. To overcome this limitation, heat transfer enhancers may be inserted within a PCM.

In a review article, mainly focused on PCMs, Sharma et al. [10] present a brief but broad discussion on the advantages of thermal energy storages systems, the different types of thermal energy storage, and common storage materials, including their limitations. The authors conclude that PCMs are effective means of storing thermal energy due to the high energy storage density and to the fact that thermal energy is stored in an isothermal fashion. PCMs have a large range in melting temperatures so it is possible to design PCM heat storage systems for specific applications.

2.2. Solar Cookers with Heat Storage. Most solar cooker designs do not include heat storage, limiting the usefulness of such solar cookers to periods of uninterrupted direct sunshine. Akinwale [11] suggests that despite the recognized benefits of solar cooking regarding energy and environment, these constraints are the limiting factors for the acceptance of solar cooking as an alternative to conventional cooking. The benefits of the inclusion of heat storage in solar systems are recognized in several studies $[10,12]$.

Important research efforts have been made on heat storage materials for solar power applications as well as for a range of other applications, but very few have targeted heat storage options for solar cookers [10]. There is currently an increasing interest in investigating solar thermal energy storage systems for small scale solar cooking applications $[8,13-15]$.

In 1994, Wilson (referenced in [11]) designed a concept of a double-reflector solar cooker with heat storage. The reflectors are two parabolas in which the secondary reflector is located at the focal point of the primary reflector and directs the sun rays to the heat storage positioned underneath. Akinwale [11] developed and tested a prototype of solar cooker using Wilson's concept in 2006. Lithium Nitrate placed in modules was used as a storage material and the modules were placed in an insulated container, after charging. Tests showed that this system was able to store heat at constant temperature about $258^{\circ} \mathrm{C}$ up to 6 hours and thus capable of providing useful heat for cooking during this period. The storage material was also able to remain at temperatures above the boiling point of water, at normal atmospheric pressure, for up to $25 \mathrm{hrs}$.

Buddhi and Sahoo [16] used Stearic acid as TES in a box type solar cooker and tested the system with cooking load and without cooking load. The results were compared with the results of performance studies on conventional solar box cookers reported in the literature. The results with the PCM storage documented the feasibility of solar cooking even in absence of solar radiation.

Sharma et al. [17] designed, developed, and tested a solar cooker based on an evacuated tube solar collector integrated with a PCM (commercial grade erythritol). Water was used as HTF and a pump circulated the water from the collector to the storage. The authors performed boiling tests after charging the storage until temperatures of $130^{\circ} \mathrm{C}$. However, the ratio of the storage energy to the solar radiation was somewhat 
low and the system was considered costly for the low income communities.

Schwarzer et al. [18] developed several versions of a solar cooker, with and without TES. The system uses thermal oil as HTF with natural circulation in copper pipes. The pipes can be extended behind a wall to allow for in-door cooking. The thermal efficiency was experimentally determined using a water boiling test and was found to be about $40 \%$.

Saxena et al. [19] investigated different PCMs to find out their suitability as TES for cooking purposes using a box type solar cooker. Stearic acid was selected as an appropriate PCM and used in solar box cooker experiments, with and without the heat storage. Stearic is, due to its availability and low cost (in India), commonly used as a heat storage material. Performance studies of the two solar cookers were conducted using stagnation temperature tests and water boiling tests at load conditions. The cooker with the heat storage showed good performance.

Mussard et al. [15] performed a comparative experimental study on direct cooking with the SK14 concentrator [15] and an indirect cooker with a parabolic trough system with naturally circulating oil from the absorber to a "Solar Salt" heat storage. The thermal performance comparison was made with a water boiling test and a meat frying test. A challenge with cooking on top of a heat storage is that imperfections on the surface limit the thermal contact between a cooking pot and the storage surface. The top plate of the storage can be used directly as a frying surface. A cooking pot in the SK14 is illuminated directly, including the sides of the pot, whereas a flat frying pan is more difficult to use in the SK14.

In this work, a double-reflector system for direct illumination of a heat storage is tested. The work is an extension of the work done by Foong et al. [8], now with an upscaled version of the test setup. The objective is to estimate the energy efficiency of a system where PCM based solar thermal batteries are charged directly by solar illumination. The batteries are sized to be portable and to provide suitable energy for cooking of one meal. Residual heat can be used for space heating, and the heat battery can be recharged the next day.

\section{Test System}

A system comprising a primary reflector, a secondary reflector, and a PCM HS containing a binary mixture of Sodium Nitrate and Potassium Nitrate $\left(\mathrm{NaNO}_{3}-\mathrm{KNO}_{3}\right)$ at mixing ratio of $60: 40(\mathrm{~mol} \%)$ was used in this experiment.

The primary dish is made of aluminum (previously produced as an antenna) and covered with reflective aluminum tiles with reflectivity of $90 \%$. The diameter is $2000 \mathrm{~mm}$ and the height is $377 \mathrm{~mm}$. The diameter of the secondary dish is $305 \mathrm{~mm}$ and the height is $67 \mathrm{~mm}$ and was also covered with Kind-man reflective film w/self-adhesive model nr K-MF98 with reflectivity of $98 \%$. To keep the secondary reflector at optimum position above the primary reflector, 4 legs are used as supports using adjustable clamps. The reflectors were built in the context of a Master thesis; for more details see Sivertsen [20].

A cylindrical aluminum container with $190 \mathrm{~mm}$ internal diameter, $200 \mathrm{~mm}$ height, and $5 \mathrm{~mm}$ wall thickness was used

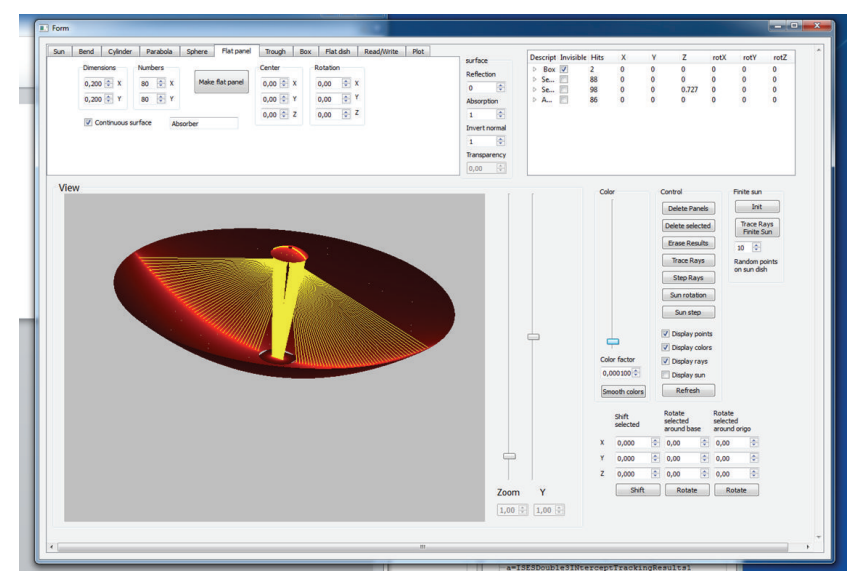

FIGURE 1: Demonstration of the double-reflector system with a ray tracer [21].

as a holder for the PCM. Aluminum fins are used for the heat transfer from the aluminum top plate absorber to the PCM. The storage unit was built and analyzed computationally by Foong [13] and modified in the context of a Master thesis [20] by increasing the thickness of the aerogel insulation from $1 \mathrm{~cm}$ to $5 \mathrm{~cm}$.

In the present study the absorber is integrated to the storage. The concentration ratio for the system was found to be 110 and is given

$$
C_{\text {op }}=\frac{A_{\text {ap }}}{A_{\mathrm{ab}}} .
$$

$A_{\text {ap }}$ is the area of aperture of the primary reflector, and $A_{\mathrm{ab}}$ is the area of the absorber.

The primary reflector has a center hole of $290 \mathrm{~mm}$ to allow sun rays coming from the secondary reflector to hit the top absorber plate of the stationary heat storage below the primary reflector; see the schematics in Figure 1 and the photo in Figure 5. With both reflectors sharing the same focal point, the rays coming from the secondary will be parallel. The distance $d$ between the vertexes of the two reflectors is then $d=f_{p}+f_{s}$, where $f_{p}=662 \mathrm{~mm}$ and $f_{s}=67.2 \mathrm{~mm}$ is the focal length of primary and secondary reflector, respectively. With a slight further elevation of the secondary reflector, the rays will focus somewhat on the storage absorber plate, as demonstrated with a ray tracer in Figure 1.

The double reflector (Figure 2) has a two-axis sun tracking system where two motors with gears (Figure 3) are controlled with a commercial controller having 4 light diodes. The horizontal axis of rotation is close to the surface of the heat storage and the vertical axis of the rotation is at the centre of the storage, shown in Figure 4.

While the double-reflector tracks the sun, the PCM storage remains stationary in a vertical position underneath the primary reflector. Thus, in its rotational motion around the horizontal axis, the double-reflector rotates relative to the storage. With this setup, the solar distribution on the top plate of the heat storage will be nonsymmetric, as the illumination will come at an angle. The storage is not allowed to tilt but kept 


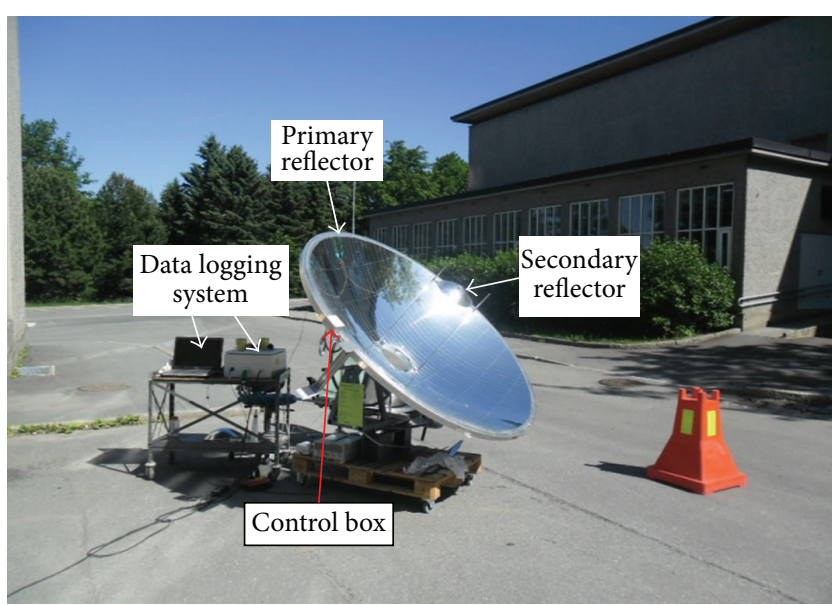

FIGURE 2: Double-reflector and data logging systems.

horizontal not to risk leakage of the melted PCM from the top rim. The top plate is on purpose not hermetically closed. Some opening to the ambient pressure will ensure that the storage is not pressurized as the salt expands upon melting.

Three thermocouples positioned at different levels in the PCM HS, Figure 5, were recorded with a data logger (LabView program) during the heating of the storage. The forth thermocouple was positioned on the secondary reflector to monitor its temperature.

A thermographic camera FLIR E60, Figure 6, from Fluke Company was also used to scan temperatures at the absorbing top plate of the storage as shown in Figure 7.

The thermal efficiency is the ratio of stored heat to the solar radiation received from sun. It is determined from measurements in a time interval $\Delta t$ :

$$
\eta_{\mathrm{th}}=\frac{E_{\mathrm{stored}}}{A_{\mathrm{ap}} I_{\mathrm{av}} \Delta t}
$$

where $I_{\mathrm{av}}$ is the average beam intensity:

$$
I_{\mathrm{av}}=\frac{1}{\Delta t} \int_{\Delta t} I(t) d t
$$

The heat stored in the PCM HS during the experiment can be calculated from the temperature recordings and (1). A practical way of implementing the specific melting energy is by allowing the melting temperature to span a temperature range and use an apparent heat capacity in this range. We apply the heat capacities for Solar Salt as suggested experimentally by Foong et al. [8]:

$$
c_{P}\left(\mathrm{~kJ} / \mathrm{kg}^{\circ} \mathrm{C}\right)= \begin{cases}0.75 & T<110^{\circ} \mathrm{C} \\ 4.1 & 110^{\circ} \mathrm{C} \leq T \leq 120^{\circ} \mathrm{C} \\ 1.4 & 120^{\circ} \mathrm{C}<T<210^{\circ} \mathrm{C} \\ 12 & 210^{\circ} \mathrm{C} \leq T \leq 220^{\circ} \mathrm{C} \\ 1.6 & T>220^{\circ} \mathrm{C} .\end{cases}
$$

\section{Results and Discussion}

A test was conducted where the system was left in the sun with an active solar tracking; see the picture in Figure 2. The rises in the temperatures in the storage were logged and are shown in Figure 8.

The direct sun intensity is recorded continuously on the roof of a neighboring building and is shown for the test in Figure 8 as well. The values are quite typical for sunny days in Trondheim $\left(800-900 \mathrm{~W} / \mathrm{m}^{2}\right)$, where the air is normally clear and dry. The beam intensity during the experiment varied between 870 and $830 \mathrm{~W} / \mathrm{m}^{2}$ during the test which lasted for about 4 hours.

The secondary reflector must be positioned in such a way as to maximize the reflection process of the solar radiation from the primary reflector and direct it to the top plate absorber of the PCM HS. When this position is attained the temperature at the surface of the secondary reflector is close to ambient temperature. When not in an optimized position, concentrating effects from the primary dish can cause local heating of the secondary dish. In the current test case the secondary dish temperatures were typically $70-80^{\circ} \mathrm{C}$.

An infrared camera (IR) was used to scan temperatures at different points of the system.

Figure 7 shows a thermographic picture of the top absorber of PCM HS. As can be seen, the illumination at an angle is not symmetric and the hot spot temperature in this case was $277^{\circ} \mathrm{C}$ at the top plate absorber of the PCM HS. This temperature is $57^{\circ} \mathrm{C}$ higher than the temperature for the onset of melting process of the mixture. The temperatures are thus moderate, which means there is little risk of overheating of neither the aluminum nor the salt during the charging. The moderate heat transfer rates also mean that the temperature gradients inside the salt will be moderate.

Figure 8 shows the transient temperature profiles at three points within the HS, the behavior of beam radiation, and the temperature on the secondary reflector.

The shape of the temperature curves and the final temperature recordings of about $250^{\circ} \mathrm{C}$ indicate that the salt was melted at the end of the experiment. From 14:33 PM to 15:45 PM the temperature profiles tend to be more constant in time, with temperatures values at about the solid-liquid melting point. The inflection point is at $124^{\circ} \mathrm{C}$; Foong et al. [8] report melting temperatures of $216^{\circ} \mathrm{C}$.

Data from thermocouple one $\left(T_{1}\right)$ which measures the temperature in the air gap at the top section of the storage reveals that air temperature is close to the salt temperature $\left(T_{2}\right.$ and $\left.T_{3}\right)$, meaning that the air is stagnant, and convective losses from air leakage into the internal of the storage are small. In addition, it should be also noted that temperatures given by the sensors at the three different positions of the PCM HS exhibit little difference, probably due to the fast conduction in the fins compared with the salt.

The efficiency was computed from (4). The stored energy comprise the energy absorbed by the container + Fins + Top plate absorber, all made of aluminum and the total mass of $3.8 \mathrm{~kg}$ and the energy absorbed by $7.5 \mathrm{~kg}$ of PCM. The system was heated from $23^{\circ} \mathrm{C}$ to $250^{\circ} \mathrm{C}$ in approximately 4 hours. 


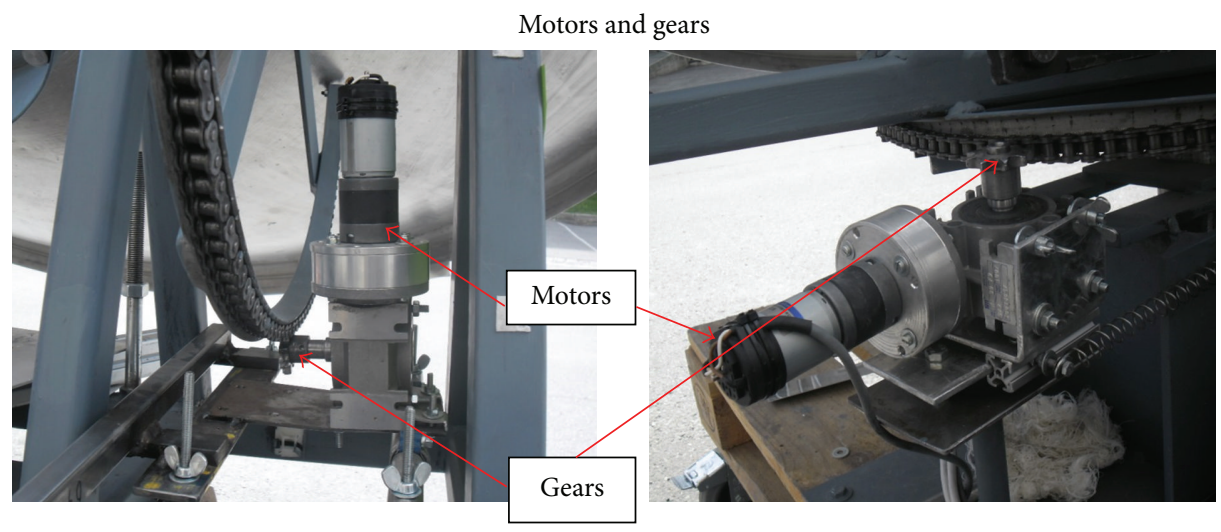

FigURE 3: (a) Motor and gear for rotation around hozontal axis. (b) Motor and gear for rotation around vertical axis.

PCM heat storage

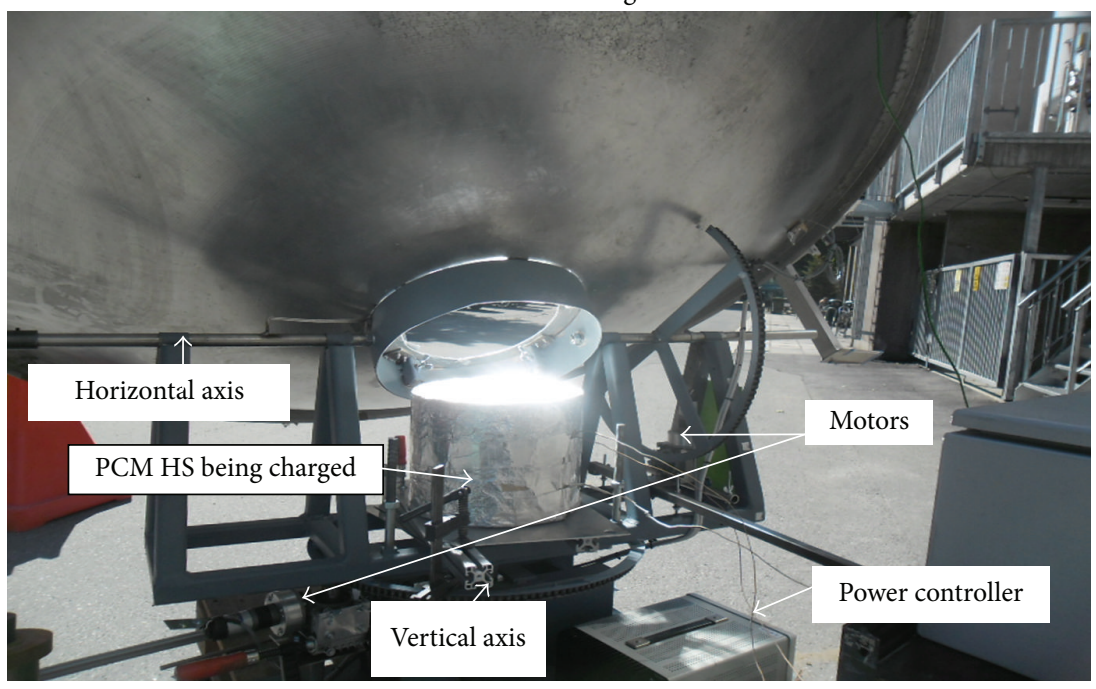

Figure 4: This picture illustrates PCM HS and the tracking system.
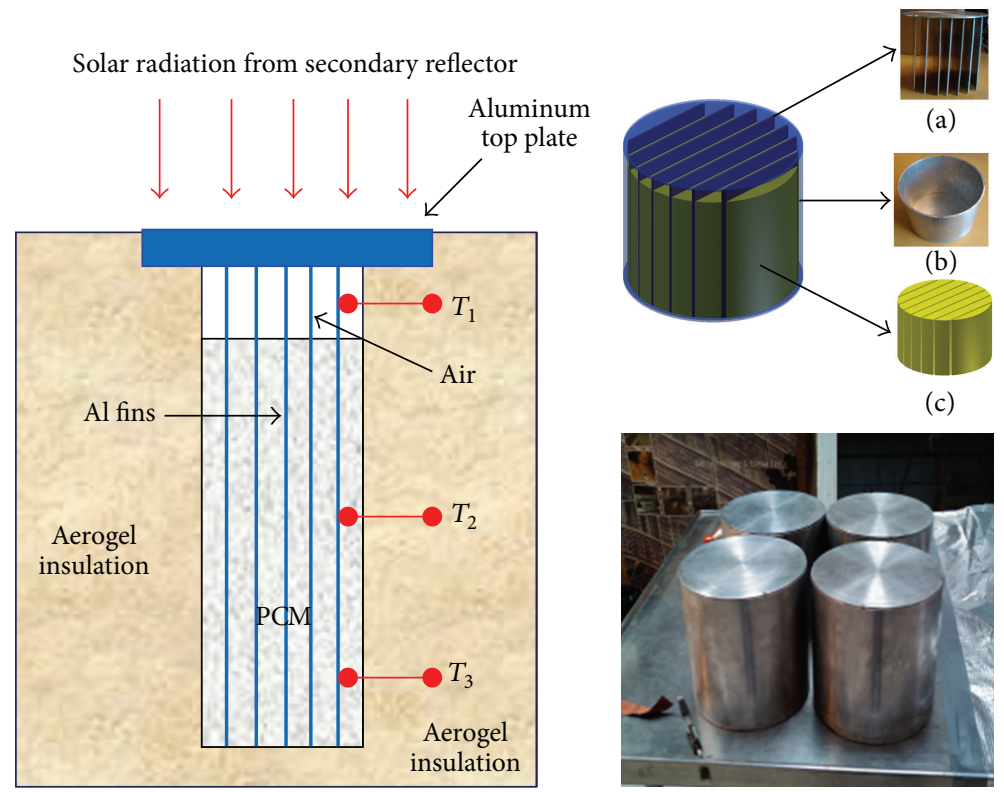

(c)

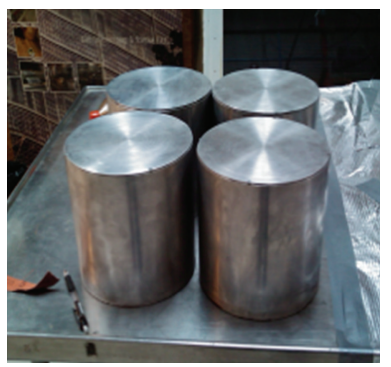

FigURE 5: Schematic representation and pictures of PCM HS used in the setup, adapted from Foong et al. [8]. 

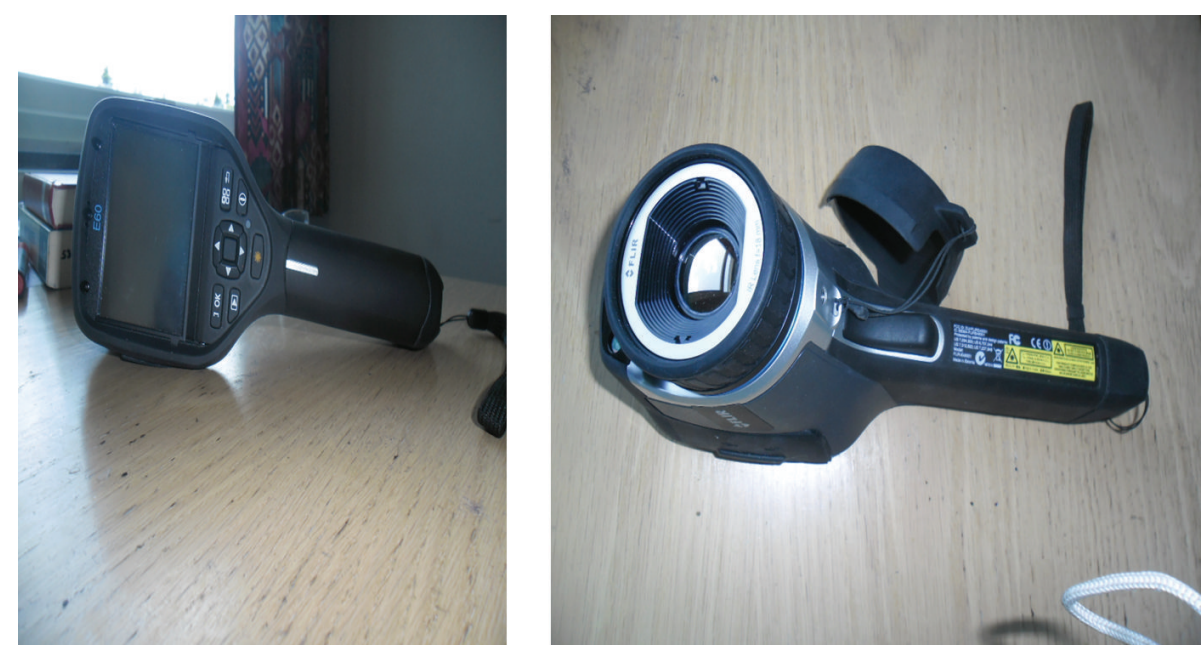

FIGURE 6: Thermographic camera used to take infrared pictures.

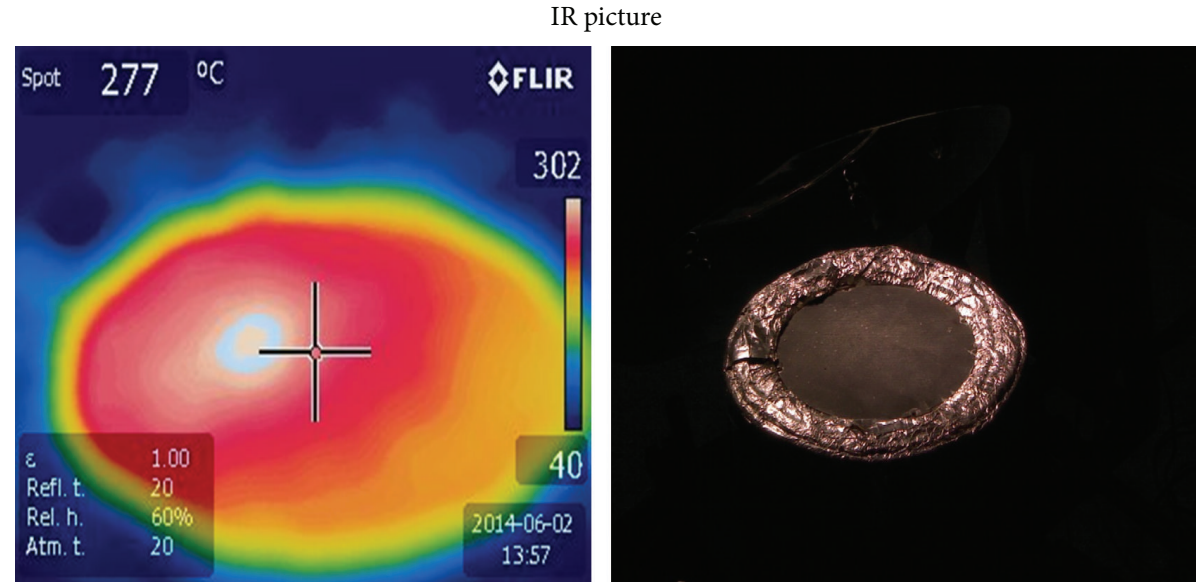

FIGURE 7: IR picture of the PCM HS top plate absorber during measurements.

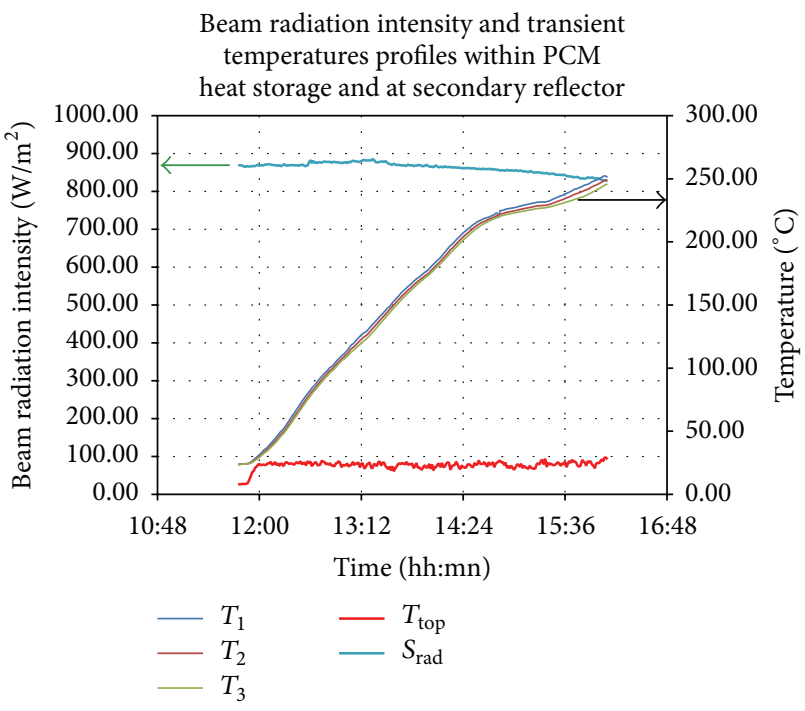

FIGURE 8: Recorded beam radiation intensity and temperature profiles at three positions within PCM HS and at the secondary reflector surface (08.06.2014 experiment).
Relevant thermophysical properties are given in Table 1.

The average beam radiation during the measurement was estimated to be $850 \mathrm{~W} / \mathrm{m}^{2}$ which implies that around $38.0 \mathrm{MJ}$ of energy from the sun was received by the primary reflector and by the end of the test, nearly 5.0 MJ of thermal energy was stored in HS.

Then, the charging efficiency of the system was found to be about $13 \%$. This is a rather low value; a solar heat collector is expected to yield much higher efficiencies. Higher efficiencies should be expected in solar countries where the solar noon angle is more vertical than at the test site in Norway.

There are several sources of losses in the transfer of sunshine to heat in this system.

(i) Optical losses are the case where not all the radiation reflected by the primary reflector reaches the top absorber plate. Optical losses are difficult to assess directly. With two reflectors, the error propagation due to surface imperfections is amplified. The accuracy in the positioning of the secondary reflector is also a source of error. The secondary reflector does 
TABLE 1: Thermophysical properties of PCM and aluminum [8].

\begin{tabular}{lccc}
\hline & Aluminum & & PCM \\
\hline Density & $2700 \mathrm{~kg} / \mathrm{m}^{3}$ & Enthalpy of fusion & $108.67 \mathrm{~kJ} / \mathrm{kg}$ \\
Specific heat capacity & $900 \mathrm{~J} /(\mathrm{kg} \cdot \mathrm{K})$ & Phase transition Enthalpy & $31.91 \mathrm{~kJ} / \mathrm{kg}$ \\
Mass & $3.8 \mathrm{~kg}$ & Temperature of fusion & $216.0^{\circ} \mathrm{C}$ \\
& & Mass & $7.5 \mathrm{~kg}$ \\
\hline
\end{tabular}

heat up, signifying losses as a consequence of the nonideal reflectivity of the surface. The vertical stationary position of the PCM HS also leads to optical losses when the sun comes down to low altitudes and the rays fall on the storage surface at a low angle. Theoretically the storage can be positioned to capture all rays, but the visual inspection of the illumination clearly shows that the optical inaccuracies give high losses; at low solar altitude angles the solar radiation from the secondary reflector falls outside the top plate absorber of the PCM.

(ii) The present solar tracking system has worked quite well for other test configurations, but the tracking accuracy becomes more critical for the doublereflector case [21].

(iii) Radiative and convective heat losses from the top plate absorber can be large. As it is exposed to the ambient without shielding or cover, the wind conditions will affect the losses quite a lot. The aerogel insulation on the sides of the storage seems to provide sufficient side insulation.

The system can be optimized by increasing the accuracy on the optical part. The secondary reflector could be somewhat larger, with elliptic rather than parabolic form, and with a high quality reflection surface. The support for the secondary reflector needs to be sturdy and allows for fine tuning of the position.

Convective heat losses can be reduced by constructing a glass shield on top of the storage. This will, however, also give some added optical losses due to partial reflection of sun rays from the glass surface, in particular at low illumination angles.

\section{Conclusions}

A double reflector system has been tested for direct illumination of latent heat storage. The idea with the setup is that a portable heat battery can be placed for charging in a fixed focus position, as the reflection system is following the sun during the day. Charging of "Solar Salt" storage is demonstrated, where the solar beam from the reflectors heats the top plate of the storage. The heat is conveyed to the salt through conducting fins, and the heat flow is reversed during cooking or frying on the top plate after sun set. The melting temperature of Solar Salt is about $220^{\circ} \mathrm{C}$ and is as such suitable for cooking or frying.

The charging of the heat battery is demonstrated, but the heat collection efficiency is rather low, about $13 \%$. The system can be optimized by ensuring a higher optical accuracy on the reflectors and by limiting the heat losses from the top plate.

\section{Competing Interests}

The authors declare that they have no competing interests.

\section{Acknowledgments}

The authors are thankful to Paul Svendsen and Marius Østnor for technical assistance during the work. The project is part of a collaboration project on renewable energy between Norway and several African universities, under the Norwegian Energy and Petroleum Program.

\section{References}

[1] IRENA, Mozambique: Renewables Readiness Assessment, 2012, http://www.irena.org.

[2] B. C. Cuamba, M. L. Chenene, G. Mahumane, D. Z. Quissico, J. Lovseth, and P. O'Keefe, "A solar energy resources assessment in Mozambique," Journal of Energy in Southern Africa, vol. 17, no. 4, pp. 76-85, 2006.

[3] A. Chikukwa, Modelling of a solar stove: small scale solar concentrating system with heat storage [Ph.D. thesis], Norwegian University of Science and Technology, 2008.

[4] R. Zolho, Mudanças Climáticas e as Florestas em Moçambique, Amigos da Floresta/Centro de Integridade Pública, 2010.

[5] N. I. Nijegorodov, K. R. S. Devan, H. Simao, and R. Mabbs, "Comprehensive study of solar conditions in Mozambique: the effect of trade winds on solar components," Renewable Energy, vol. 28, no. 12, pp. 1965-1983, 2003.

[6] Solar Cooker International (SCI), http://solarcooking.wikia .com/wiki/Solar_Cookers_International_Network_\%28Home $\% 29$.

[7] P. Otte, "Limits and possibilities of institutional solar cooking in Mozambique," in Proceedings of the Ises Solar World Congress, Kassel, German, 2011.

[8] C. W. Foong, O. J. Nydal, and J. Løvseth, "Investigation of a small scale double-reflector solar concentrating system with high temperature heat storage," Applied Thermal Engineering, vol. 31, no. 10, pp. 1807-1815, 2011.

[9] G. Glatzmaier, Summary Report for Concentrating Solar Power. Thermal Storage Workshop, NREL, 2013, http://www.osti.gov/ bridge.

[10] A. Sharma, V. V. Tyagi, C. R. Chen, and D. Buddhi, "Review on thermal energy storage with phase change materials and applications," Renewable and Sustainable Energy Reviews, vol. 13, no. 2, pp. 318-345, 2009.

[11] P. F. Akinwale, Development of an asynchronous solar-powered cooker [M.S. thesis], Department of Mechanical Engineering, Massachusetts Institute of Technology, 2006. 
[12] A. Sharma, S. N. Mishra, P. Kumar, and B. P. Singh, "Development and thermal analysis of new class of storage elements," International Journal of Engineering Research \& Technology, vol. 1, no. 4, pp. 1-12, 2012.

[13] C. W. Foong, Experimental and numerical investigations of a small scale double-reflector concentrating solar system with latent heat storage [Ph.D. thesis], Norwegian University of Science and Technology, 2011.

[14] D. Okello, Rock bed stove suitable for solar cookers with thermal energy heat storage systems [Ph.D. thesis], Makerere University, Kampala, Uganda, 2012.

[15] M. Mussard, A. Gueno, and O. J. Nydal, "Experimental study of solar cooking using heat storage in comparison with direct heating," Solar Energy, vol. 98, pp. 375-383, 2013.

[16] D. Buddhi and L. K. Sahoo, "Solar cooker with latent heat storage: design and experimental testing," Energy Conversion and Management, vol. 38, no. 5, pp. 493-498, 1997.

[17] S. D. Sharma, T. Iwata, H. Kitano, and K. Sagara, “Thermal performance of a solar cooker based on an evacuated tube solar collector with a PCM storage unit," Solar Energy, vol. 78, no. 3, pp. 416-426, 2005.

[18] K. Schwarzer, M. E. V. Silva, and L. L. P. Santana, Recent Developments of the Solar Cooking System with or without Heat Storage for Families and Institutions, 2006.

[19] A. Saxena, S. Lath, and V. Tirth, "Solar cooking by using PCM as a thermal heat storage," MIT International Journal of Mechanical Engineering, vol. 3, no. 2, pp. 91-95, 2013.

[20] V. Sivertsen, Direct charging of a solar thermal battery [M.S. thesis], Norwegian University of Science and Technology (NTNU), Trondheim, Norway, 2013.

[21] O. J. Nydal, "Ray tracing for optimization of a double reflector system for direct illumination of a heat storage," Energy Procedia, vol. 57, pp. 2211-2220, 2014, Proceedings of the 2013 ISES Solar World Congress. 

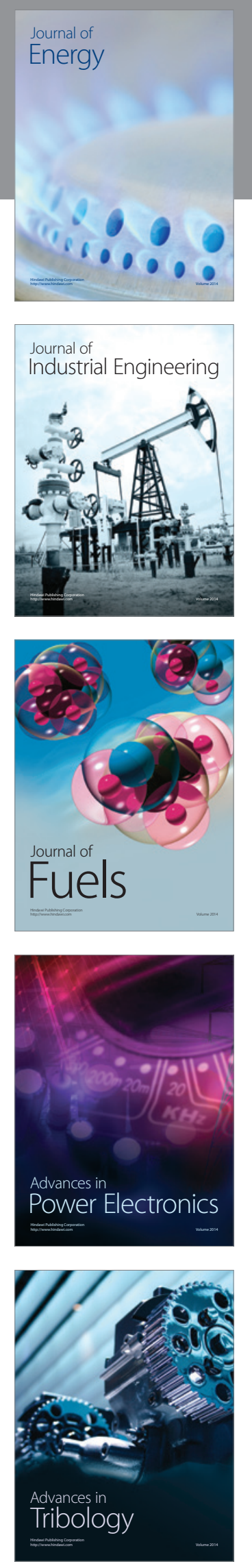
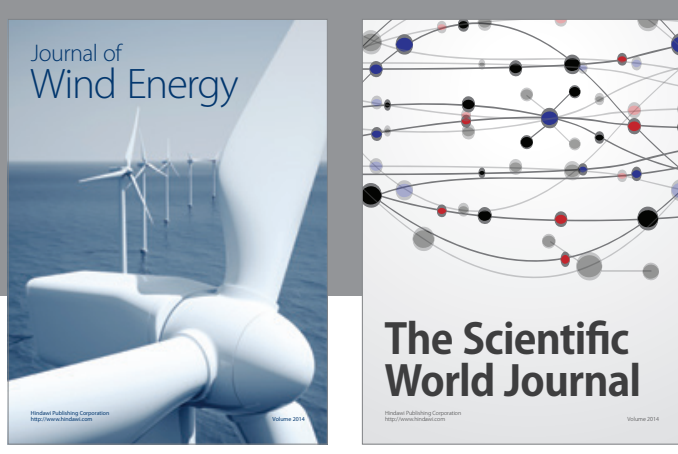

The Scientific World Journal
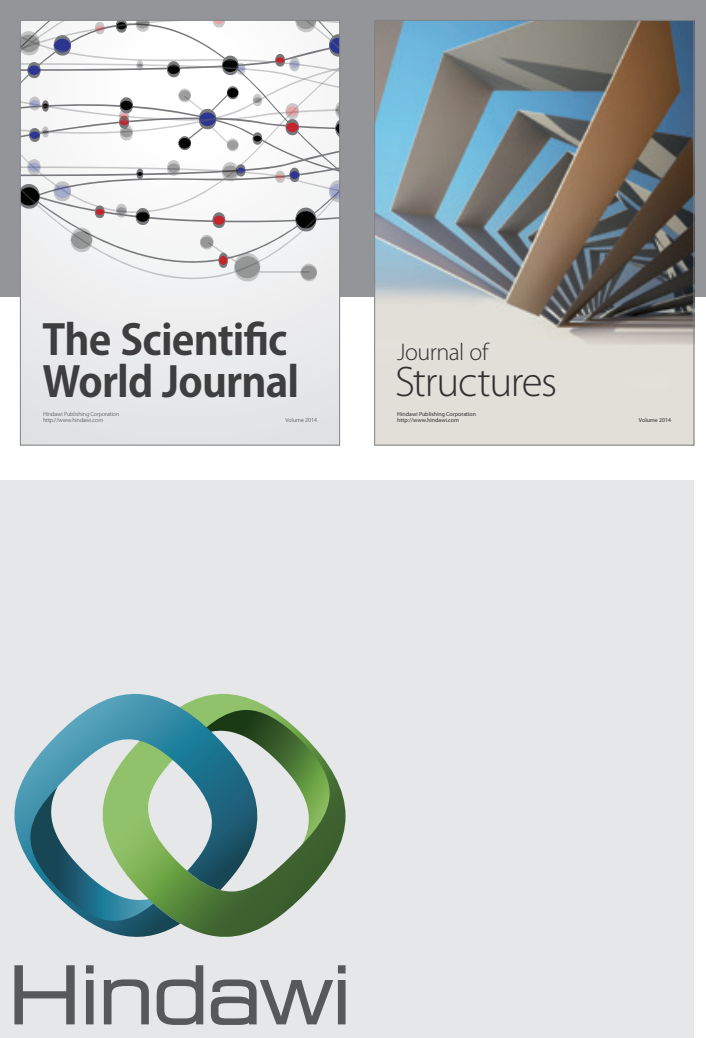

Submit your manuscripts at

http://www.hindawi.com
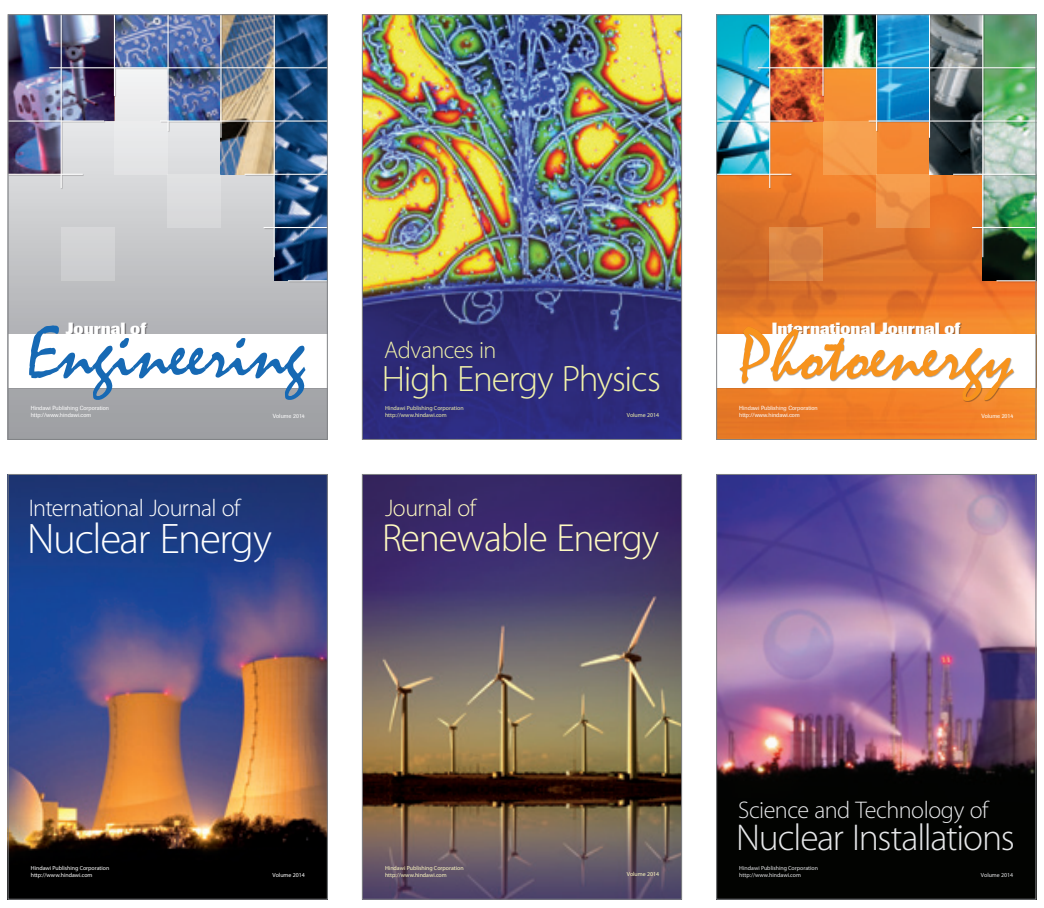
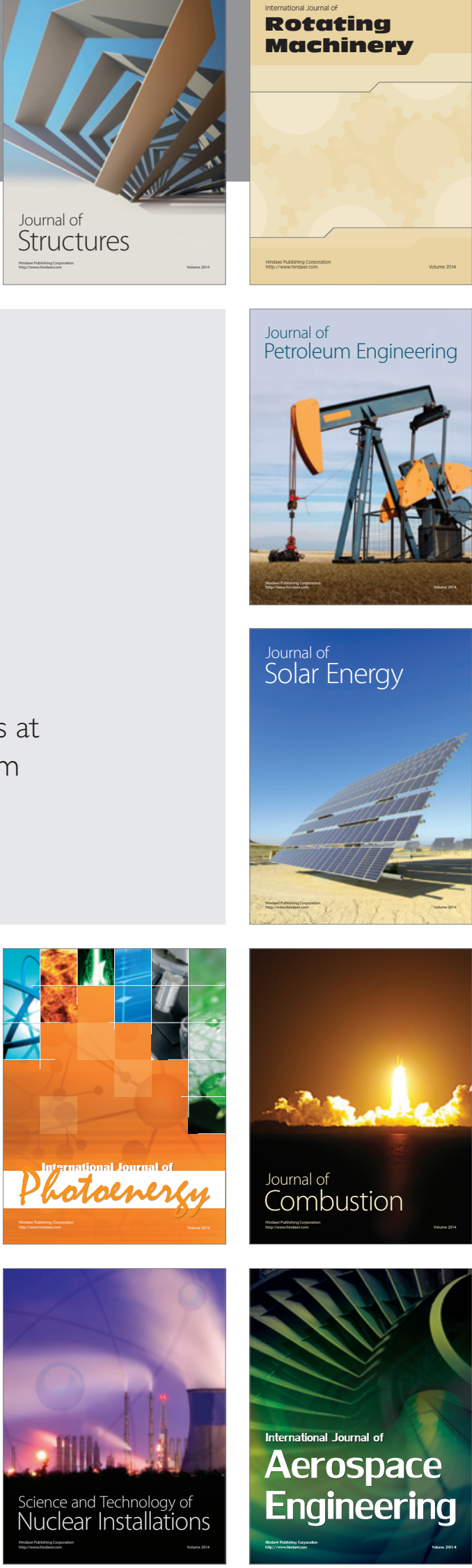